\title{
Movimentos Migratórios sob a Perspectiva do Direito à Saúde: Imigrantes Bolivianas em São Paulo ${ }^{(*)}$
}

\author{
MIGRATORY MOVEMENTS FROM THE PERSPECTIVE OF HEALTH RIGHTS: \\ BOLIVIAN IMMIGRANT WOMEN IN SÃO PAULO
}

Tatiana Chang Waldman ${ }^{(* *)}$

\section{RESUMO}

A despeito de a saúde ser um direito constitucionalmente garantido a todos e um dever do Estado, é necessário questionar se seu acesso universal e igualitário efetivamente alcança a população de estrangeiros residentes no Brasil. O objetivo deste trabalho foi identificar a potencial existência de entraves ao acesso aos serviços de saúde por parte de imigrantes bolivianas residentes na cidade de São Paulo. A hipótese era a de que, apesar da universalidade do acesso à saúde ser garantida pela legislação pátria, as imigrantes teriam ressalvas em relação à utilização destes serviços. As informações alcançadas com a pesquisa sugerem, no entanto, que a grande maioria das entrevistadas já havia sido assistida, pelo menos uma vez, por algum serviço médico na cidade de São Paulo, e indicam, ainda, que foi alto o índice de procura por medidas preventivas de promoção da saúde, particularmente o atendimento pré-natal, sugerindo, inclusive, um elevado índice numérico de consultas para este mesmo tipo de atendimento por parte das entrevistadas. Para a realização deste projeto, ademais da pesquisa bibliográfica, foram realizadas entrevistas com vinte e oito mulheres imigrantes, no Centro de Apoio ao Migrante (CAMI/SPM), nos meses de abril e maio de 2010, que serviram para identificar a percepção do grupo estudado com relação ao sistema de saúde nacional e, ainda, compreender o comportamento do mesmo diante da legislação nacional.

(*) Este artigo foi apresentado como monografia de conclusão do "VIII Curso de Especialização em Direito Sanitário" promovido pela Faculdade de Saúde Pública da Universidade de São Paulo, desenvolvido sob orientação da $\operatorname{Prof}^{-2}$ Dr $^{a}$ Ana Lúcia Pastore Schritzmeyer. Os resultados desta pesquisa foram apresentados no "6oㅡㄹ Encontro Anual da ANDHEP - Direitos Humanos, Cidades $e$ Desenvolvimento", em 17 de setembro de 2010, em Brasília.

$\left.{ }^{* *}\right)$ Mestranda em Direito pela Faculdade de Direito da Universidade de São Paulo, especialista em Direito Sanitário pela Faculdade de Saúde Pública da Universidade de São Paulo; advogada da Instituição "Centro de Apoio ao Migrante" (CAMI/SPM). São Paulo/SP-Brasil. E-mail: $<$ tatiana.waldman@gmail.com>. Recebido em 10.09.10. Revisado em 11.11.10. Aprovado em 17.11.10. 


\section{Palavras-chave:}

Atenção à Saúde; Direitos Humanos; Imigração Boliviana; São Paulo; Saúde de Minorias.

\section{ABSTRACT}

Health is a right guaranteed by the Brazilian Constitution to all people within our borders and a State's duty, but it should be examined whether foreign residents living in Brazil have effectively universal and equal access to health. The purpose of the present study was to identify potential barriers to health service access by Bolivian immigrant women living in the city of São Paulo. Our hypothesis was that despite universal access to health care guaranteed by Brazilian law, immigrant women would encounter barriers to the use of these services. However, it was found that respondents have received care at least once in any service in São Paulo; it was also revealed a high demand for prevention and health promotion programs, especially prenatal care with a high rate of prenatal consultations. Data was collected through literature review and interviews conducted with 28 Bolivian immigrant women at the Immigrant Support Center (CAMI/SPM) in the city of São Paulo during April and May 2010. The interviews allowed to assess the perceptions of the group studied regarding the Brazilian National Health Care System and to understand their behavior.

\section{Keywords:}

Bolivian Immigration; Health Care; Human Rights; Minority Health; São Paulo City.

\section{INTRODUÇÃO}

O Brasil, por seu histórico de país receptor de correntes migratórias e por sua população composta pelas mais distintas mesclas de nacionalidades, aparenta não apresentar restrições à chegada de todo aquele que nele vê uma oportunidade de nova pátria ${ }^{(1)}$. Tal perspectiva, no entanto, dissimula o viés adotado pela política imigratória brasileira que tem

(1) MENEZES, Lená Medeiros. Movimentos e políticas migratórias em perspectiva histórica: um balanço do século XX. In: CASTRO, Mary Garcia (Coord.). Migrações internacionais: contribuições para políticas. Brasília: CNPD, 2001. p.123-124. 
como essência a seletividade na permissão de ingresso de estrangeiros e apresenta restrições à entrada dos considerados indesejáveis ao país.

Em sentido contrário ao direcionamento de tal política, no ano de 2009, algumas medidas foram tomadas pelo governo brasileiro as quais, de alguma maneira, beneficiaram determinado número de imigrantes, como a comumente denominada "Lei de Anistia de Estrangeiros" (Lei n. 11.961/09, regulamentada por meio do Decreto n. 6.893/09) e o Acordo de Livre Residência MERCOSUL (Decreto n. 6.964/09) e MERCOSUL, Chile e Bolívia (Decreto n. 6.975/09).

A legislação(2) que aborda a temática, entretanto, continua a mesma desde a década de 1980, data em que o Brasil ainda se encontrava em um regime de exceção e que trazia a questão migratória como um assunto de segurança nacional, sem fazer qualquer menção à questão dos direitos fundamentais das pessoas que por qualquer motivo migravam para o país. Tal postura está, notoriamente, em desacordo com os princípios de proteção aos direitos humanos presentes na atual Constituição brasileira, que trata os estrangeiros como sujeitos de direitos.

Pela negligência em se discutir as causas estruturais e suas consequências no contexto nacional de crescentes fluxos migratórios, bem como a problemática das políticas migratórias adotadas pelo Estado brasileiro, a retórica predominante na enunciação dos fenômenos imigratórios atuais para o país traz, quase sempre, um viés negativo. Nas palavras de Denise Fagundes Jardim $^{(3)}$, banaliza-se "o problema" da imigração como se fosse um problema do imigrante.

Dificilmente se menciona, ao se tratar das imigrações internacionais recentes para o Brasil, os benefícios que esta movimentação de pessoas traz para o país. Em um contexto em que as temáticas relacionadas aos êxitos e às contribuições dos imigrantes nos diversos campos sociais, culturais e econômicos são comumente desvalorizadas, pessoas originárias de países com menor desenvolvimento econômico e que imigram para países mais desenvolvidos acabam arcando com a responsabilidade pela maioria das mazelas e desgraças existentes no Estado de destino ${ }^{(4)}$.

(2) No sistema jurídico brasileiro, a possibilidade de ingresso do estrangeiro em território nacional é matéria de direito constitucional, com reserva à lei ordinária, que traz os preceitos das condições de admissibilidade e permanência. (CAHALI, Yussef Said. Estatuto do Estrangeiro. São Paulo: Saraiva, 1983. p. 73.) A Lei n. 6.815/80 (o Estatuto do Estrangeiro) com as alterações da Lei n. 6.964/81 e regulamentada pelo Decreto n. $86.715 / 81$, é a lei ordinária que estabelece as diretrizes gerais da situação jurídica dos estrangeiros no Brasil. Tramita, atualmente, no Parlamento brasileiro, o Projeto de Lei n. 5.655/09, que, se aprovado, passará a ser a legislação vigente sobre estrangeiros no país. (3) JARDIM, Denise Fagundes (Org.). Cartografias da imigração: interculturalidade e políticas públicas. Porto Alegre: Ed. UFRGS, 2007. p. 9.

(4) CAVALCANTI, Leonardo. Imigrante na cidade: paradoxos e pleonasmos. Travessia: revista do migrante, São Paulo, ano 18, n. 51, p. 24, jan./abr. 2005. 
O imigrante é comumente visto com desconfiança pelos membros da sociedade receptora ${ }^{(5)}$, principalmente quando sua presença não está autorizada e quando existe a percepção de que poderá competir com os cidadãos locais pelos bens, serviços públicos e postos de trabalho. Desta forma, inevitavelmente, sofre com as diferenças culturais, a precarização das condições de trabalho e as dificuldades de integração na sociedade, que incluem, dentre outros, os problemas de acesso aos serviços básicos, o preconceito e a discriminação.

Pode-se dizer que a situação da pessoa que migra é, no mínimo, conflitante. Sob o ponto de vista do país de sua nacionalidade, ela é denominada emigrante por quem a considera ausente. Sob outro ponto de vista, o do destino que foi encarado como objetivo e alvo da decisão de partir, o mesmo sujeito é visto como imigrante: aquele que chega do exterior ${ }^{(6)}$.

Não são, contudo, apenas as diferentes denominações que se referem ao mesmo sujeito que pontuam sua situação conflitante, mas também seu estatuto social. O emigrante é um nacional ausente, tem a maioria de seus direitos tutelados no país de origem e, possivelmente, diminuídos seus deveres e obrigações inerentes à condição de cidadão nacional. Inteiramente oposta é sua situação como imigrante, qualificada como uma pessoa que vem de outro país e encontra uma sociedade, provavelmente, desconhecida na qual terá que se inserir, sujeitando-se às leis que ali estão em vigor. Leis que regularão as relações desenvolvidas ao longo de sua permanência, na condição de cidadão estrangeiro, e limitarão diversos direitos e prerrogativas a que os nacionais desse país estão sujeitos ${ }^{(7)}$.

Neste contexto, o fluxo imigratório de bolivianos para a cidade de São Paulo é, infelizmente, tido por parte da população nacional como mais um ônus para a sociedade brasileira. Trata-se de um fluxo que já se realiza há aproximadamente seis décadas e hoje é composto, em sua grande maioria, por trabalhadores e trabalhadoras informais do setor têxtil - caracterizado, majoritariamente, pelo intenso ritmo de trabalho, baixa remuneração e ambiente de trabalho insalubre - e que possui, ainda, um alto índice de imigrantes em condição indocumentada(8).

(5) COMISSÃO MUNDIAL SOBRE AS MIGRAÇÕES INTERNACIONAIS. As migrações num mundo interligado: novas linhas de ação. 2005, p. 42.. Disponível em: <http://www.mte.gov.br/cni/ relatorioglobal.pdf>. Acesso em: 20 ago. 2008.

(6) ROCHA-TRINDADE, Maria Beatriz. (Org.). Sociologia das migrações. Lisboa: Universidade Aberta, 1995. p. 31.

(7) Id., loc. cit.

(8) São usuais as denominações "irregular", "regular", "legal” e "ilegal”, quando se trata de caracterizar os fluxos migratórios, termos em que se aceita o argumento de que a imigração é considerada uma violência contra o Estado. O melhor é o uso do termo "indocumentado", adotado em situações em que os pressupostos legais exigidos para entrada e permanência no Estado receptor não foram respeitados. Tal é o termo que passaremos a utilizar deste ponto em diante. 
A situação vulnerável em que se encontram muitos destes migrantes, sejam eles documentados ou não, se agrava pelas desvantagens de não terem o conhecimento dos costumes e práticas legais brasileiras e da acessibilidade aos serviços sociais disponíveis, sem contar com as barreiras de linguagem e cultura ${ }^{(9)}$. Como consequência, parte desta população, muito provavelmente, não se utilizará dos serviços públicos a que tem direito, como saúde e educação.

No que diz respeito à saúde(10), a despeito da Constituição Federal de 1988 estabelecer, pela primeira vez, categoricamente, no art. 196, que ela é direito de todos e dever do Estado, e de a legislação nacional(11) afirmá-la não apenas como um direito fundamental de todo ser humano, como também um direito social, conforme previsto no art. 6으 da Carta Magna ${ }^{(12)}$, é necessário analisar se este acesso universal e igualitário à saúde efetivamente alcança esta população de imigrantes que vem surgindo de maneira crescente no contexto atual nacional.

Faz-se necessário destacar a importância de se discutir a questão do acesso à saúde dos migrantes, tendo em vista que os mesmos enfrentam diversas modificações e adaptações em seu modo de vida, o que pode resultar em alterações, também, no campo de sua saúde ${ }^{(13)}$.

Existem motivos para que se suspeite do menor acesso dos imigrantes aos serviços de saúde. As ressalvas, possivelmente, se dariam pelo desconhecimento ou não domínio da língua, que impede ou dificulta a comunicação e o acesso à informação sobre os riscos a que estão sujeitos ${ }^{(14)}$; pela

(9) GRAEME, Hugo. Migrações internacionais não documentadas: uma tendência global crescente. Travessia: revista do migrante, São Paulo, ano 11, n. 30, p. 11, jan./abr. 1998.

(10) Neste sentido, segundo Sueli Gandolfi Dallari, examinando o campo da formalização constitucional, já ocorreu no Brasil o reconhecimento da saúde como um direito (CF, art. 6º). In: DALLARI, Sueli Gandolfi. Direito sanitário. Disponível em: <http://www.saude.ba.gov.br/conferenciaST2005/cdrom/ CD\%20colet\%C3\%A2nea\%20leis\%20e\%20textos/Artigos/10.doc>. Acesso em: 30 out. 2006.

(11) De acordo com o art. 196 da Constituição Federal brasileira: "A saúde é direito de todos e dever do Estado, garantido mediante políticas sociais e econômicas que visem à redução do risco de doença e de outros agravos e ao acesso universal igualitário às ações e serviços para sua promoção, proteção e recuperação." Neste sentido, a Lei n. 8.080/90, Lei Orgânica a Saúde (LOS), em seu art. 2 afirma, ainda: "A saúde é um direito fundamental do ser humano, devendo o Estado prover as condições indispensáveis ao seu pleno exercício. $\S 1^{\circ} \mathrm{O}$ dever do Estado de garantir a saúde consiste na formulação e execução de políticas econômicas e sociais que visem à redução de riscos de doenças e de outros agravos e no estabelecimento de condições que assegurem acesso universal e igualitário às ações e aos serviços para a sua promoção, proteção e recuperação." In: BRASIL. Ministério da Saúde. Secretaria de Atenção à Saúde. Departamento de Ações Programáticas Estratégicas. Legislação em saúde: caderno de legislação de saúde do trabalhador. 2. ed. rev. ampl. Brasília: Ministério da Saúde, 2005. p. 36-38.

(12) OLIVEIRA, Sebastião Geraldo. Proteção jurídica à saúde do trabalhador. São Paulo: LTr, 2002. p. 121.

(13) MONTEIRO, Ivete. Ser mãe Hindu: práticas e rituais relativos à maternidade e aos cuidados à criança na cultura Hindu em contexto de imigração. Dissertação (Mestrado em Comunicação em Saúde) - Universidade Aberta, Lisboa, 2005. p. 230. (Observatório da Imigração, Colecção Teses, Tese nr. 9. Lisboa: ACIDI).

(14) Id. Ibid., p. 82. 
situação econômica que os impede de sair do trabalho (levando em conta que a maioria dos imigrantes originários da Bolívia trabalha no setor têxtil e recebe pela produção); pela situação indocumentada de sua residência; e, talvez, pelo local de origem dos mesmos, já que muitos dos imigrantes bolivianos que chegam à São Paulo já haviam migrado dentro do próprio país de origem, do meio rural para as cidades, podendo ter um entendimento diverso da necessidade de buscar serviços de saúde.

Com fundamento na relevância do tema e da existência de poucas pesquisas a respeito do acesso do imigrante aos serviços de saúde na cidade de São Paulo(15), a proposta deste artigo é identificar a potencial existência de entraves ao acesso aos serviços de saúde por parte de imigrantes bolivianas residentes na referida metrópole.

Foi feita a opção de estudar e analisar a população feminina do grupo de imigrantes bolivianos. Tal posição se justifica pela população numerosa de imigrantes desta nacionalidade residentes na cidade(16) e pela percepção de uma mudança de perfil do fluxo migratório de nacionais da Bolívia para a capital paulista.

Se em um período anterior (1985-1994), a grande maioria dos imigrantes bolivianos era composta por homens na faixa dos 15 aos 35 anos ${ }^{(17)}$ que vinham sozinhos em busca de trabalho, hoje o cenário é diferente. Há cidades, como Corumbá/MS, em que a imigração de bolivianos é marcadamente feminina(18). E em São Paulo, dados de atendimento (não publicados) do Centro de Apoio ao Migrante (CAMI/SPM), referentes ao período da segunda quinzena de julho a 30 de dezembro do ano 2009, demonstram um percentual muito próximo de mulheres e homens imigrantes, estando os últimos em pequena vantagem numérica ${ }^{(19)}$.

(15) Citamos como exemplo: SILVA, Elaine Cristina Camillo. Rompendo barreiras: os bolivianos e o acesso aos serviços de saúde na cidade de São Paulo. Travessia: revista do migrante, São Paulo, ano 22, n. 63, p. 26-31, jan./abr. 2009.

(16) De acordo com dados extraídos do site do Ministério da Justiça, dos cerca de 43.000 imigrantes que regularizaram a sua situação migratória no país com a anistia para estrangeiros de 2009, os nacionais da Bolívia foram os maiores beneficiados pela medida, com aproximadamente 17.000 inscritos, sendo cerca de 16.300, só no Estado de São Paulo. In: ANISTIA a estrangeiros irregulares atende expectativa do governo. Disponível em: <http://portal.mj.gov.br/data/Pages/ MJA5F550A5ITEMIDBA915BD3AC384F6C81A1AC4AF88BE2D0PTBRNN.htm>. Acesso em: 10 jun. 2010. (17) Em pesquisa realizada por Sidney Antonio da Silva a partir de dados levantados na Pastoral do Migrante, foram consultadas 332 fichas entre os anos de 1985 a julho de 1994, e notou-se que a maioria, $74,2 \%$ era do sexo masculino e $25,8 \%$ do sexo feminino. In: SILVA, Sidney Antonio. Costurando sonhos: trajetória de um grupo de imigrantes bolivianos em São Paulo. São Paulo: Paulinas, 1997. p. 91.

(18) No que diz respeito à imigração em Corumbá, a população dos chefes de família e seus cônjuges nascidos na Bolívia, 289 no total, 65\% (188) são mulheres e 35\% (101) são homens. In: FUSCO, Wilson; SOUCHAUD, Sylvain. Uniões exogâmicas dos imigrantes bolivianos na fronteira do Brasil. Travessia: revista do migrante, São Paulo, ano 22, n. 63, p. 32-38, jan./abr. 2009. p. 34.

(19) Dos 3.122 imigrantes bolivianos atendidos pelo CAMI/SPM no período relatado de 2009, 1.715 $(54,9 \%)$ eram homens e $1.407(45,1 \%)$ eram mulheres. 
É interessante destacar, ainda, que a ênfase do estudo no acesso aos serviços de saúde pela população feminina se deu pelo fato de que, geralmente, a procura por serviços médicos por parte desta população é maior do que a da população masculina ${ }^{(20)}$. Desta forma, identificar problemas no acesso deste grupo levaria a uma visão privilegiada do problema.

As hipóteses investigadas nesta pesquisa, antes de iniciada a coleta de dados básicos sobre a relação do grupo estudado com o Sistema Único de Saúde (SUS), eram de que a universalidade do acesso aos serviços de saúde, garantida constitucionalmente pelo sistema jurídico brasileiro, não impedia que imigrantes residentes no Brasil continuassem a ter ressalvas em relação à utilização deste serviço; de que os mesmos não adotavam, costumeiramente, medidas de saúde preventiva, recorrendo aos serviços hospitalares tão somente em caso de emergência ou em situações em que as doenças já se encontravam em fases avançadas; por último, de que o tratamento de doenças crônicas ou mesmo acompanhamentos importantes, tais como o pré-natal, eram, muitas vezes, adiados por tempo indeterminado.

Os dados colhidos pela pesquisa ora realizada verificaram, no entanto, que tais hipóteses, ao menos no universo estudado, não traduzem a realidade destas imigrantes nacionais da Bolívia. As informações alcançadas com a pesquisa sugerem que a grande maioria das entrevistadas já havia sido assistida, pelo menos uma vez, por algum serviço médico na cidade de São Paulo, e indicam, ainda, que foi alto o índice de procura por medidas preventivas de promoção da saúde, particularmente o atendimento pré-natal, sugerindo, inclusive, um elevado índice numérico de consultas para este mesmo tipo de atendimento por parte das entrevistadas.

\section{METODOLOGIA}

Trata-se de estudo descritivo, de caráter exploratório. A área de estudo foi o município de São Paulo e a população analisada foi a formada por imigrantes bolivianas, independentemente de sua situação migratória no país, com no mínimo 18 anos de idade, residentes no município de São Paulo, que buscaram o atendimento no Centro de Apoio ao Migrante (CAMI/SPM) para regularizar sua situação migratória, renovar o visto de permanência, procurar assistência jurídica ou mesmo participar de atividades realizadas pela Instituição, entre elas plenárias livres, cursos de computação e português, no período que engloba os meses de abril e maio do ano de 2010.

(20) Verificar: DAHROUGE, Simone et al. An evaluation of gender equity in different models of primary care practices in Ontario. BCM Public Health, Londres, v. 10. 2010. Disponível em: <http://www.biomedcentral.com/1471-2458/10/151>. Acesso em: 07 mar. 2010. 
A escolha do Centro de Apoio ao Migrante (CAMI/SPM) ${ }^{(21)}$ se deu por ser ele um espaço criado especificamente para atuar na promoção e defesa dos direitos humanos dos migrantes, bem como garantir-lhes o acesso gratuito à orientação jurídica especializada, atendimento para a regularização migratória, promoção cultural e atividades de formação para a cidadania, inclusão digital e social e por grande parte de seu público ser formada por imigrantes sul-americanos residentes na cidade de São Paulo. Ademais, por ser um ambiente em que os sujeitos que participaram do estudo sentiam-se à vontade para expressar suas opiniões e anseios.

Trabalhou-se com uma amostra intencional. Os critérios de inclusão foram: mulheres, de nacionalidade boliviana, nascidas até o ano de 1991, que estivessem há mais de um ano, residindo no município de São Paulo. Os critérios de exclusão, portanto, foram: nascimento em ano posterior ao de 1991, residência por período menor que um ano no município de São Paulo, e os indivíduos que, pela barreira do idioma, não conseguissem responder ao questionário.

Tomaram-se como fontes de dados os formulários utilizados nos atendimentos do Centro de Apoio ao Migrante (CAMI/SPM) (Anexo 1) e as informações obtidas por meio de entrevistas, as quais foram registradas em um questionário estruturado e padronizado (Anexo 2) e, posteriormente, armazenadas eletronicamente para análise.

\section{A realização das entrevistas}

Faz-se necessário enfatizar a limitação temporal da pesquisa, tendo em vista ser a mesma um trabalho de conclusão do "VIII Curso de Especialização em Direito Sanitário" promovido pela Faculdade de Saúde Pública da Universidade de São Paulo, bem como o alto número de imigrantes bolivianas residentes na cidade, o que impossibilitou a aplicação do questionário à totalidade de indivíduos que estavam de acordo com os critérios de inclusão indicados. Desta forma, optou-se por atingir um grupo específico desta população, para, a partir do mesmo, ponderar as informações alcançadas.

Ao todo foram realizadas 28 entrevistas, com uso de questionário. Antes da aplicação do mesmo, o projeto de pesquisa era sinteticamente apresentado às entrevistadas, a privacidade dos registros e o anonimato eram garantidos, bem como a solicitação de participação consentida era requerida ${ }^{(22)}$. Todas as entrevistas se deram no Centro de Apoio ao Migrante (CAMI/SPM).

(21) Em 22 de julho de 2005, o Serviço Pastoral dos Migrantes (SPM), entidade de cunho civil, filantrópico e sociopastoral, sem fins lucrativos, fundada em 31 de outubro de 1985 e ligada ao Setor Pastoral Social da Conferência Nacional dos Bispos do Brasil (CNBB), inaugurou o Centro de Apoio ao Migrante (CAMI/SPM).

(22) A pesquisa observou as recomendações da Resolução n. 196 de 10 de outubro de 1996 Conselho Nacional de Saúde para Pesquisa Científica em Seres Humanos, sendo aprovado o seu 
É importante trazer à tona o fato de que, a despeito do questionário ser padronizado, cada entrevista teve a sua dinâmica própria. Houve timidez por parte de algumas entrevistadas, que se limitaram a responder às perguntas de forma objetiva, mas também houve extroversão por parte de outras, que, em suas respostas, transcenderam o conteúdo das perguntas, enriquecendo, desta forma, o conteúdo da pesquisa.

A pesquisa empírica teve por objetivo perceber o sistema normativo do ponto de vista das entrevistadas. Desse modo, foi possível compreender o comportamento do grupo ora estudado diante da legislação nacional, por meio de dados coletados a partir dos formulários e questionários.

\section{NOTAS SOBRE O SISTEMA DE SAÚDE NACIONAL A PARTIR DA PERSPECTIVA DAS IMIGRANTES ${ }^{(23)}$}

\section{Caracterização do universo de estudo}

A caracterização geral do universo de estudo pode ser observada na tabela I. Grande parte das entrevistadas, 46,5\% (13/28), se encontrava na faixa etária dos 26 a 30 anos; 75\% (21/28) tinham como origem o departamento de La Paz; 71,4\% (20/28) vieram ao Brasil utilizando ônibus como meio de transporte; $60,7 \%$ (17/28) alegaram como motivo para emigrar a esperança de encontrar um emprego ou um emprego melhor, e 57,1\% (16/ 28) atuavam, profissionalmente, à época, como costureiras.

\section{Tabela I - Características sociodemográficas e relativas ao processo migratório da população estudada}

\begin{tabular}{|l|c|c|}
\hline CARACTERÍSTICA & NÚMERO N = 28 & PORCENTAGEM (\%) \\
\hline Idade (em anos) & & \\
\hline 20-25 anos & 6 & 21,4 \\
\hline 26-30 anos & 13 & 46,5 \\
\hline 31-36 anos & 6 & 21,4 \\
\hline 37 anos & 3 & 10,7 \\
\hline
\end{tabular}

desenvolvimento pelo Comitê de Ética em Pesquisa da Faculdade de Saúde Pública da Universidade de São Paulo. As entrevistas somente foram efetuadas após a assinatura do consentimento informado. A base de dados criada a partir dessas entrevistas foi armazenada eletronicamente, sem informações que permitam identificar as pessoas incluídas, de forma a garantir a privacidade dos registros e o anonimato dos sujeitos da pesquisa, utilizando-se os dados assim obtidos exclusivamente para os propósitos desse estudo.

(23) É importante ressaltar que os trechos de algumas entrevistas transcritos neste artigo, quando as mesmas se davam em espanhol, foram traduzidos pela autora para o português. 


\begin{tabular}{|c|c|c|}
\hline CARACTERÍSTICA & NÚMERO N = 28 & PORCENTAGEM (\%) \\
\hline \multicolumn{3}{|l|}{$\begin{array}{l}\text { Ano em que chegou ao } \\
\text { Brasil }\end{array}$} \\
\hline $1986-2000$ & 8 & 28,6 \\
\hline 2001-2005 & 10 & 35,7 \\
\hline 2006-2009 & 10 & 35,7 \\
\hline \multicolumn{3}{|l|}{$\begin{array}{l}\text { Departamento de origem } \\
\text { na Bolívia }\end{array}$} \\
\hline La Paz & 21 & 75,0 \\
\hline Potosi & 3 & 10,7 \\
\hline Oruro & 2 & 7,1 \\
\hline Cochabamba & 1 & 3,6 \\
\hline Santa Cruz de La Sierra & 1 & 3,6 \\
\hline \multicolumn{3}{|l|}{ Cidade de entrada no Brasil } \\
\hline Corumbá/MS & 11 & 39,3 \\
\hline Foz do Iguaçu/PR & 5 & 17,9 \\
\hline Cáceres/MT & 2 & 7,1 \\
\hline Não informado & 10 & 35,7 \\
\hline \multicolumn{3}{|l|}{ Meio de transporte utilizado } \\
\hline Ônibus & 20 & 71,4 \\
\hline Não informado & 8 & 28,6 \\
\hline \multicolumn{3}{|l|}{ Motivo da migração } \\
\hline Trabalho & 17 & 60,7 \\
\hline Outros & 1 & 3,6 \\
\hline Não informado & 10 & 35,7 \\
\hline \multicolumn{3}{|l|}{ Profissão atual } \\
\hline Costureira & 16 & 57,1 \\
\hline Comerciante & 2 & 7,1 \\
\hline Educadora & 1 & 3,6 \\
\hline Cabeleireira & 1 & 3,6 \\
\hline Médica & 1 & 3,6 \\
\hline Não trabalha & 1 & 3,6 \\
\hline Não informado & 6 & 21,4 \\
\hline
\end{tabular}




\begin{tabular}{|l|c|c|}
\hline CARACTERÍSTICA & NÚMERO N = 28 & PORCENTAGEM (\%) \\
\hline Profissão anterior & & \\
\hline Estudante & 5 & 17,8 \\
\hline Costureira & 4 & 14,2 \\
\hline Comerciante & 3 & 10,7 \\
\hline Advogada & 1 & 3,6 \\
\hline Cabeleireira & 1 & 3,6 \\
\hline Empregado em empresa & 1 & 3,6 \\
\hline Artesã & 1 & 3,6 \\
\hline Dona de casa & 1 & 3,6 \\
\hline Médica & 1 & 3,6 \\
\hline Não informado & 10 & 35,7 \\
\hline
\end{tabular}

Merece ênfase o fato de, na comunidade boliviana residente na cidade de São Paulo, ser forte a presença dos "imigrantes laborais", que veem o ato de emigrar como uma fuga à crise econômica e política pela qual passa a Bolívia e como uma possível solução para a busca de trabalho e melhores oportunidades de vida para si mesmos e suas respectivas famílias. Desta forma, os motivos da emigração boliviana são eminentemente econômicos. A grande maioria desses imigrantes cruza a fronteira brasileira em busca de trabalho e de uma vida digna na capital paulista.

\section{O acesso ao sistema de saúde na cidade de São Paulo}

Das 28 mulheres bolivianas participantes dessa pesquisa, apenas três delas $(10,7 \%)$ não se utilizaram dos serviços médicos desde que chegaram ao Brasil. O que significa que $89,3 \%$ (25/28) das entrevistadas acessaram o sistema de saúde na cidade de São Paulo.

Interessante notar a justificativa pela não utilização do serviço. Tão somente uma alegou que não o fez porque não falava português e não conhecia nenhum serviço médico, e que quando esteve doente, acabou por esperar que a doença passasse sozinha. Essa entrevistada chegou ao Brasil em março de 2009. Outra, por ser médica, afirmou nunca ter precisado ir ao serviço de saúde na cidade, porque resolvera suas necessidades, até aquele momento, com a automedicação. E, por último, a terceira não necessitou de qualquer atendimento médico desde que chegara ao país, em 2007, mas afirmou que já havia levado seu filho ao posto de saúde.

A maioria das mulheres que procuraram os serviços de saúde $76 \%$, (19/25) utilizou a assistência pública (SUS), enquanto $24 \%(6 / 25)$ delas buscaram auxílio tanto em estabelecimentos públicos como privados. 
Desse mesmo grupo, a maioria, 52\% (13/25), gerou filhos na cidade de São Paulo. Das mulheres entrevistadas que tinham filhos brasileiros ${ }^{(24)}, 61,5 \%$ (8/13) possuíam dois filhos nascidos no Brasil e 38,5\% (5/13) geraram somente um filho brasileiro. Todas as treze imigrantes que tiveram filhos no Brasil procuraram a assistência médica no período da gravidez, e no que diz respeito ao atendimento pré-natal, 76,9\% (10/13) foram atendidas de cinco a dez vezes, e $23,1 \%(3 / 13)$ mais de dez vezes. Todas essas mulheres (13) realizaram o parto em hospitais, e todas as crianças que nasceram no Brasil foram vacinadas.

\section{Avaliação das dificuldades no acesso ao atendimento médico}

Questionadas sobre a existência, ou não, de dificuldades para conseguir um bom atendimento em função do idioma, por um lado, 52\% (13/25) acreditam que a questão linguística resultou em obstáculos na hora do auxílio médico, no entanto, por outro lado, 48\% das entrevistadas (12/25) afirmaram não entender o idioma como empecilho para o acesso à assistência médica no Brasil.

Das que afirmaram a existência de problemas na comunicação entre imigrantes e médicos, enfermeiros e funcionários administrativos, foram relatadas dificuldades delas para explicarem os sintomas que apresentavam e expressarem suas ansiedades e preocupações diante da percepção de que parte da equipe hospitalar não entendia a fala em castelhano. Muitas mencionaram a celeridade da fala de funcionários/enfermeiros/médicos e a reação negativa dos mesmos quando declaravam não entender o português.

As entrevistadas que declararam a inexistência de barreiras linguísticas no acesso aos serviços de saúde apresentaram percepções particulares. Uma imigrante que chegou ao Brasil no ano de 2003, por exemplo, disse entender bem o português, utilizando como tática para o entendimento, por parte dos brasileiros, a fala pausada do castelhano; outras duas, que chegaram ao país há, aproximadamente, dez anos, disseram que, no início, as dificuldades eram grandes, mas que, atualmente, entendem bem o português e acreditam que se fazem entender.

No que diz respeito às dificuldades de se ausentarem do trabalho para ir às consultas médicas, 56\% (14/25) afirmaram não ser esse um problema, e 44\% $(11 / 25)$ consideraram ser esta uma barreira ao acesso a serviços médicos.

(24) De acordo com o art. 12, I, "a", da Constituição Federal Brasileira, são brasileiros natos "os nascidos na República Federativa do Brasil, ainda que de pais estrangeiros, desde que estes não estejam a serviço de seu país" (grifo nosso). In: VADE MECUM SARAIVA. 7. ed. São Paulo: Saraiva, 2009. p.13. 
Destaca-se o fato de que, além das comerciantes, donas de oficinas de costura e trabalhadoras que se consideram autônomas, que, estão no grupo das que alegaram não ter qualquer problema em obter licença no trabalho para acessar a assistência médica, encontram-se muitas costureiras que declaram a compreensão de donos de oficinas de costura no que diz respeito aos cuidados com a saúde.

No sentido contrário, muitas outras entrevistadas que exercem, atualmente, a profissão de costureiras, declararam a oposição e o incômodo de donos de oficinas no que tange à saída do trabalho para a utilização de serviços médicos.

\section{Avaliação do grau de satisfação no atendimento médico}

A respeito da percepção sobre a existência, ou não, de diferenciação de atendimento no campo de assistência à saúde para brasileiros e estrangeiros, $72 \%$ (18/25) das entrevistadas declararam que esta diferenciação existe $^{(25)}, 24 \%$ (6/25) que não há qualquer distinção de tratamento e 4\% (1/25) não souberam responder à pergunta.

A avaliação da maioria das entrevistadas enfatiza o caráter negligente por parte de alguns médicos, enfermeiros e funcionários administrativos no atendimento de estrangeiros - é importante enfatizar que muitas deixaram claro que não eram todos(26). Foram problematizados, dentre outros fatos, a pouca atenção dada às queixas, havendo baixo grau de satisfação, por parte de algumas, no que tange à qualidade do atendimento: "dizem que está tudo bem, mas não te examinam"; "tive muita dor e eles não fizeram nada; eles nos ignoram"; "os médicos e funcionários não dão muita atenção, demoram a atender os estrangeiros mais do que os brasileiros"; "os brasileiros têm um atendimento mais rápido que os bolivianos"; "na hora de fazer o cadastro eles nem olham para você, nem me perguntaram e escreveram que eu era indígena"; "eles não têm paciência para ouvir o espanhol".

Outro ponto que merece destaque é a conduta de determinados profissionais de saúde: "médicos e funcionários gritam, brigam, olham diferente para os estrangeiros"; "não falam fácil, te olham feio, empurram. Eles dizem que não entendem o que eu falo, mas eu sei que eles entendem"; "os brasileiros pensam que o imigrante não fala a língua e sempre tem que estar abaixo"; "os brasileiros são bem atendidos e nós não, os bolivianos são muito humildes por isso eles berram com a gente, gritam".

(25) Nas palavras de uma das entrevistadas: "Eles tratam melhor os brasileiros que os bolivianos." (26) Segundo duas entrevistadas: "algumas pessoas são muito mal-educadas, algumas pessoas falam seja bem-vinda"; "alguns funcionários te tratam de maneira diferente dos brasileiros, mas não são todos." 
Todavia, uma das entrevistadas sugere outro entendimento sobre o tema: "eles diferenciam pela aparência (vestimenta, conhecimentos) e não pela nacionalidade".

A falta de sensibilidade, compreensão ou mesmo desconhecimento de alguns profissionais de saúde, diante dos projetos de vida idealizados por muitas destas imigrantes também pôde ser percebida por meio das entrevistas: "Eles perguntam por que você não está em seu país, falam que poderiam estar atendendo um brasileiro e não um estrangeiro"; "os médicos falam que a gente trabaIha demais, e falam para a gente voltar para a nossa terra; eles não compreendem que na Bolívia está difícil; sabemos que o posto (de saúde) não é para nós".

A questão das dificuldades encontradas pela falta de documentos também foi referida: "os brasileiros têm o acesso facilitado; para os estrangeiros são pedidos mais documentos"; "uma vez me perguntaram se eu tinha documentos, eu disse que não; me tiraram da fila e me deixaram esperando por muito tempo".

A percepção do aumento do número de imigrantes bolivianos nos serviços de saúde da cidade também foi relatada(27), mas houve diferentes entendimentos das consequências de tal fato: falam (médicos e funcionários) de maneira tranquila, mas não gostam de atender; reclamam da existência de muitos bolivianos; agora o tratamento é pior porque existem muitos bolivianos na cidade e, às vezes, nos postos, têm mais bolivianos na fila que brasileiros" (a entrevistada chegou ao Brasil em 1999); "na primeira vez que fui atendida, não houve nenhuma diferença de tratamento porque não existiam muitos bolivianos aqui, mas da segunda vez fui tratada diferente" (a entrevistada chegou ao Brasil em 1997); "antigamente os bolivianos eram mal vistos, mas agora não, eles já se acostumaram com o pessoal estrangeiro" (a entrevistada chegou ao Brasil em 2003).

Interessante destacar, na fala de muitas entrevistadas, a frequente utilização da terceira pessoa, demonstrando que elas percebem a ocorrência de determinadas situações em relação aos outros, mas não em relação a si mesmas: "Vi colegas bolivianos serem maltratados"; "Os bolivianos têm medo de perguntar e acabam sendo mal atendidos"; "Tem racismo, não só no hospital; não comigo, mas com meus compatriotas; sempre falam para voltar para o seu país".

Há, também, manifestações de satisfação diante do atendimento de médicos, enfermeiros e funcionários administrativos, nos postos atendimento de saúde: "Os postos de saúde nos tratam muito bem, só tive dificuldades para marcar consulta para o meu filho"; "Sempre fui tratada muito bem, sempre dão preferência às mulheres com crianças; existem alguns que gritam nas ruas, mas nos hospitais não"; "Há muitos problemas de comunicação, as doutoras não entendem, mas nos tratam bem; gostei do atendimento nos hospitais".

(27) Disse uma entrevistada: "no posto tinha mais bolivianos que brasileiros." 
Sobre o "sentir-se desrespeitada" no desenvolvimento do atendimento médico, a maioria das entrevistadas, 76\% (19/25), declarou não ter sentido isso, em nenhum momento, $20 \%$ (5/25) entenderam que foram desrespeitadas, e $4 \%(1 / 25)$ não souberam responder à pergunta.

A propósito desta temática, poucas imigrantes deram elementos que transcendessem as respostas binárias. Foram relatadas como ações desrespeitosas a omissão no atendimento em situação de emergência e a discriminação frente aos nacionais da Bolívia( ${ }^{(28)}$. Novamente, apareceram falas em terceira pessoa, que relatavam atitudes desrespeitosas para com os outros, e afirmações de que há desrespeito nas ruas, mas não nos hospitais.

Durante o desenvolvimento de muitas entrevistas, surgiram dois temas que merecem destaque ${ }^{(29)}$ : quais mudanças seriam necessárias para se alcançar um sistema de saúde de maior qualidade e como era a assistência médica no país de origem dessas imigrantes, a Bolívia.

A respeito das mudanças indispensáveis para a melhoria no atendimento dos hospitais e postos de saúde da cidade, aspectos universais da estrutura da assistência foram lembrados: "Precisa ter mais atendimento às pessoas doentes, com mais médicos e mais funcionários"; elementos particulares foram destacados: "Eu deveria aprender a falar o português melhor" (a entrevistada chegou ao Brasil no ano de 2005); temas que apresentavam a relação estrangeiras/brasileiras foram levantados: "Todos deveriam ser tratados da mesma maneira"; mas muitas não apontaram o que poderia ser melhorado.

Mesmo destacando certas dificuldades enfrentadas nos serviços de saúde da cidade, muitas delas, ao recordarem suas percepções dos serviços de saúde na Bolívia, acabaram por destacar aspectos positivos da assistência no Brasil: "Aqui o atendimento demora muito, mas eles nos atendem"; "O atendimento no Brasil é melhor do que na Bolívia porque é de graça, na Bolívia, além da demora, temos que pagar"; "Na Bolívia, o atendimento é pago, mas se você trabalha para o governo o atendimento é gratuito; se você não tem dinheiro não é atendido, mesmo que esteja muito mal; aqui é meIhor, muitos te tratam bem e há remédios gratuitos"; "O atendimento na Bolívia era pago, aqui é tudo de graça, é melhor e tem trabalho"; "Na Bolívia, não há atendimento gratuito, só para mulheres grávidas e crianças de até 5 anos (...) lá é tudo pago".

(28) Destacam-se as percepções de duas entrevistadas: "Eles (funcionários) conversam entre eles falando que os bolivianos são sujos, tem bastante discriminação"; "Sempre tratam mal, gritam e não atendem".

(29) Percepções sobre a residência no Brasil também foram destacadas: "gosto de viver aqui." 


\section{ACESSO À SAÚDE E IMIGRAÇÃO NO BRASIL}

\section{1. $O$ direito à saúde como um direito universal e igualitário no contexto brasileiro}

É interessante destacar, neste tópico, o fato de se tratar de uma amostra intencional, a qual, portanto, não permite generalizações em relação ao universo da população de estudo.

As limitações da presente pesquisa se devem, ainda, à impossibilidade de se aplicar questionário mais completo por causa da necessidade de as perguntas serem objetivas, tendo em vista a importância de não se tomar muito tempo das entrevistadas.

Outra limitação da coleta de dados foi o fato de que alcançamos um grupo específico de imigrantes bolivianas residentes em São Paulo, pois foram entrevistadas tão somente aquelas que buscaram os serviços do Centro de Apoio ao Migrante (CAMI/SPM). Talvez, portanto, as mulheres incluídas na presente amostra podem pertencer a um grupo de imigrantes que conseguiram licenças no trabalho, possuíam o conhecimento prévio da necessidade de regularização no país para o alcance de certos direitos e da existência de uma instituição que poderia auxiliá-las, além de tempo e dinheiro para a realização dos trâmites necessários e de acesso à orientação jurídica especializada, à promoção cultural e a atividades de formação para a cidadania, inclusão digital e social.

Foram afastadas, deste modo, dentre outras, muitas mulheres que não têm condição de deixar seus ambientes de trabalho para realizar atividades diversas, bem como as que não têm o conhecimento da necessidade e possibilidade de regularização migratória no Brasil e da existência de uma instituição que poderia assisti-las gratuitamente, ou, ainda, as acometidas pela falta de recursos para a realização dos trâmites necessários. Está, portanto, por ser feita uma pesquisa que leve em conta esse grupo, o que demandaria muito mais tempo de coleta de dados e outras técnicas de abordagem.

Tendo em vista tais ressalvas, os resultados obtidos com a pesquisa sugerem algumas questões que serão, a seguir, pontuadas.

Independentemente do grau de satisfação da assistência médica oferecida, foi possível verificar que a grande maioria das entrevistadas já havia sido assistida pelo menos uma vez por algum serviço médico na cidade de São Paulo. Esses dados sugerem o contrário de uma das hipóteses iniciais desta pesquisa, a qual supunha que a universalidade do acesso aos serviços de saúde, garantida constitucionalmente pelo sistema jurídico brasileiro, não impedia que imigrantes residentes no Brasil continuassem a ter ressalvas em relação à utilização deste serviço, o que resultaria no menor acesso ao mesmo. 
Pelas limitações já explicitadas, não é possível afirmar que esses altos índices de acesso refletem a situação vivenciada por todas as imigrantes bolivianas residentes na cidade de São Paulo, sejam elas documentadas ou indocumentadas, tendo elas chegado há poucos meses ou há muitos anos.

Mas o que é possível sugerir, em matéria de análise do acesso à saúde por parte desta população, é uma mudança de percepção. Se estudos anteriores $^{(30)}$ indicavam o difícil acesso à assistência médica e a preferência, por parte dos imigrantes bolivianos, pelo uso de remédios caseiros, enfatizando o dilema de expor a condição indocumentada de muitas destas pessoas; análises mais recentes indicam uma tendência à diminuição do medo constante de abordagem pela Polícia Federal e deportação do país em virtude da ausência de documentos válidos ${ }^{(31)}$, bem como um crescimento do grau de acesso aos serviços de saúde nacionais ${ }^{(32)}$.

As outras hipóteses iniciais da pesquisa — de que os imigrantes não adotavam, costumeiramente, medidas de saúde preventiva, recorrendo aos serviços hospitalares tão somente em caso de emergência ou em situações em que as doenças já se encontravam em fases avançadas e de que o

(30) Sidney Antonio da Silva escreve: "As doenças constituem, portanto, uma grande angústia para o trabalhador da costura, porque em primeiro lugar ele está desprovido de qualquer atendimento médico. Embora os hospitais públicos atendam a qualquer pessoa, não importando a sua nacionalidade, sempre causa apreensão buscar um desses serviços porque, em primeiro lugar, há o problema da comunicação por não saber falar o português, em segundo, por não ter os documentos em dia, e em terceiro, pela qualidade do atendimento. A opção encontrada pelos costureiros é tratar os ferimentos em casa, utilizando remédios caseiros, como ervas, pó de café, o próprio óleo utilizado nas máquinas, deixavam por vezes sérias sequelas. Para outras doenças, como é o caso dos resfriados, informou uma costureira que ela usa água fervida com as cinzas das palmas abençoadas no domingo de Ramos, acrescentando-se um pouco de sal, para fazer o banho do corpo. Para abaixar a febre, ela disse utilizar urina humana para banhar a região do estômago e dos rins. E quando há o problema de dor de cabeça, ela coloca fatias de batata na região frontal da cabeça, amarradas com um pano." In: SILVA, Sidney Antonio. op. cit., p. 131.

(31) Nos dizeres de Denise Pasello Valente Novais: "Os bolivianos aceitam as condições que Ihes são impostas por uma questão de "gratidão" e honra, porque consideram que a situação aqui é melhor do que a que enfrentavam antes da migração e porque têm medo. Não tanto de serem expulsos do país, porque acabam descobrindo que isso não se concretiza de fato; eles têm medo, mesmo, de ficar sem trabalho."In: NOVAIS, Denise Pasello Valente. Tráfico de pessoas para fins de exploração do trabalho no Brasil: um estudo sobre a exploração do trabalho de bolivianos em condição análoga à de escravo na cidade de São Paulo. 2008. f. 160. Tese (Doutorado em Direito do Trabalho) - Universidade de São Paulo, São Paulo, 2008.

(32) Elaine Cristina Camillo da Silva aduz: "A unidade de saúde é vista como um espaço de convivência, por ser um dos poucos espaços frequentados pelos bolivianos adultos, fora das oficinas de costura." In: SILVA, Elaine Cristina Camillo. op. cit., p. 29. E Maria Carolina C. Madi, Ana Carolina Cassanti e Cássio Silveira afirmam: "Muito particularmente, a gravidez nas mulheres bolivianas tem constituído um importante objeto de atenção dos serviços de saúde, pois, nos últimos anos, tornou-se uma preocupação constante dos serviços de saúde nessa região." In: MADI, Maria Carolina C.; CASSANTI, Ana Carolina; SILVEIRA, Cássio. Estudo das representações sociais sobre gestação em mulheres bolivianas no contexto da atenção básica em saúde na área central da cidade de São Paulo. Saúde Sociedade, São Paulo, v. 18, supl. 2, p. 67-71, abr./jun. 2009. SciELO Brasil. Disponível em: <http://www.scielo.br/scielo.php?script=sci_arttext\&pid=S0104-1290200900060001 $1 \& \mathrm{lng}=$ pt\&nrm=iso $>$. Acesso em: 05 jun. 2010. 
tratamento de doenças crônicas ou mesmo acompanhamentos importantes, tais como o pré-natal eram, muitas vezes, adiados por tempo indeterminado - foram, também, contestadas pelos resultados obtidos neste universo de estudo.

Os dados alcançados com as entrevistas indicam que foi alto o índice de procura por medidas preventivas e de promoção da saúde, como o atendimento pré-natal, sugerindo, inclusive, um elevado número de consultas para este mesmo tipo de atendimento por parte das entrevistadas.

Desta forma, mesmo não havendo qualquer política pública específica promovida pelo Estado brasileiro, no que diz respeito a esta população de imigrantes bolivianas residentes na cidade de São Paulo, o acesso delas ao sistema da saúde nacional parece crescente.

As ressalvas destas imigrantes em relação ao acesso e à qualidade da assistência médica prestada, podem ter dificultado, mas não impedido que se mobilizassem e utilizassem os serviços de saúde disponíveis na cidade de São Paulo, sejam eles públicos ou privados.

Há que se destacar, neste ponto, em razão da inexistência de política pública específica efetivada pelo Estado brasileiro para a promoção da saúde para esta comunidade de imigrantes residente na cidade de São Paulo, a possível influência de redes sociais nos índices de acesso.

As redes sociais migratórias formadas entre os que saem e os que permanecem no país de origem são imprescindíveis quando se aborda o tema de migrações internacionais. Os imigrantes instituem entre si uma "rede" de informações e apoio objetivando não só disseminar informações do país de destino, mas também promover a adaptação do imigrante ${ }^{(33)}$.

A existência e o contato com familiares e compatriotas no país de destino é um instrumento importante para a integração dos imigrantes. No que diz respeito à saúde, a busca por assistência é, em grande parte das vezes, determinada pelas necessidades, mas, também, por experiências individuais anteriores ou experiências que familiares e conhecidos tiveram ${ }^{(34)}$.

A eficácia de tais redes entre os imigrantes bolivianos residentes na cidade de São Paulo e compatriotas residentes na Bolívia já havia sido destacada pelo pesquisador Sidney Antônio da Silva ${ }^{(35)}$ e os dados colhidos por esta pesquisa podem robustecer a força destas redes familiares de solidariedade na comunidade boliviana de São Paulo, também em âmbito de acesso à

(33) BRITO, Fausto. Os povos em movimento: as migrações internacionais no desenvolvimento do capitalismo. In: PATARRA, Neide Lopes (Coord.). Emigração e imigração internacionais no Brasil contemporâneo. 2. ed. São Paulo: FNUAP, 1995. p. 63.

(34) MONTEIRO, Ivete. op. cit., p. 75; 84.

(35) SILVA, Sidney Antonio. Hispano-americanos em São Paulo: alcances e limites de um processo de integração. Travessia: revista do migrante, São Paulo, ano 12, n. 33, p. 25, jan./abril 1999. 
saúde, as quais têm o poder de difundir as mais diversas informações sobre a vivência na cidade, incluindo os direitos e deveres dos imigrantes no país.

É imprescindível destacar, neste sentido, que não obstante a existência de uma legislação específica referente aos estrangeiros ainda em dissonância com a garantia dos direitos fundamentais de determinados imigrantes no Brasil, a Constituição Federal brasileira de 1988 possibilitou, desde a sua vigência, o acesso universal de qualquer pessoa à saúde, seja ela nacional ou estrangeira, seja um imigrante documentado ou indocumentado.

A Constituição Federal, como lei fundamental do Estado brasileiro e instrumento para a positivação de determinados valores básicos da sociedade ${ }^{(36)}$, encontra-se em harmonia com a concepção contemporânea de direitos humanos. O grande destaque aos direitos e garantias fundamentais, fez dela a Carta mais abrangente que o país já possuiu sobre a matéria.

Em sentido oposto, de acordo com o relatório de desenvolvimento humano do ano de 2009 do Programa das Nações Unidas para o Desenvolvimento (PNUD) ${ }^{(37)}$, se encontram as diretrizes de países como a França, a Alemanha e a Suécia, onde existe o denominado "dever de denunciar" a assistência médica a um imigrante indocumentado, o que, provavelmente, poderá resultar em um sentimento de receio, por parte desta população, em recorrer aos serviços de saúde no país de destino.

Assim como o Brasil, ainda de acordo com o mesmo relatório, em outros países a assistência à saúde também é acessível a todos os imigrantes, independentemente do seu estatuto legal, como é caso de Portugal( ${ }^{(38)}$ e Espanha $^{(39)}$.

\section{CONSIDERAÇÕES FINAIS}

O estranhamento entre brasileiros e imigrantes bolivianos na cidade de São Paulo, em ambientes de assistência à saúde, talvez tenha sido espe-

(36) MONTANHANA, Beatriz. A constitucionalização dos direitos sociais: a afirmação da dignidade do trabalhador. In: FREITAS JUNIOR, Antonio Rodrigues de (Org.). Direito do trabalho e direitos humanos. São Paulo: BH Ed. e Distribuidora de Livros, 2006. p. 69.

(37) PROGRAMA DAS NAÇÕES UNIDAS PARA O DESENVOLVIMENTO - PNUD. Relatório de Desenvolvimento Humano. Ultrapassar barreiras: mobilidade e desenvolvimento humanos. 2009. p. 56-57. Disponível em: <http://hdr.undp.org/en/media/HDR_2009_PT_Complete.pdf> Acesso em: 5 jun. 2010.

(38) Destaca-se na legislação portuguesa referente: Despacho n. 25.360/2001 (In: GONÇALVES, Aldina et. al. Acesso aos cuidados de saúde de comunidades migrantes: problemas e perspectivas de intervenção. Revista Portuguesa de Saúde Pública, Lisboa, v. 21, n. 1, p. 55-64, jan./jun. 2003. Disponível em: <http://www.ensp.unl.pt/dispositivos-de-apoio/cdi/cdi/sector-de-publicacoes/revista/ 2000-2008/pdfs/1-06-2003.pdf>. Acesso em: 5 jun. 2010 e Decreto-Lei n. 67/2004.

(39) PROGRAMA DAS NAÇÕES UNIDAS PARA O DESENVOLVIMENTO - PNUD. Relatório de Desenvolvimento Humano. Ultrapassar barreiras: mobilidade e desenvolvimento humanos, cit., p. 56. 
cialmente percebido por algumas entrevistadas para esta pesquisa por elas também terem vivenciado atitudes de discriminação em outros espaços públicos da cidade, como nas ruas.

Em outras palavras, questiona-se se experiências de discriminação vivenciadas em situações anteriores por estas pessoas, poderiam influenciar a sua percepção referente à discriminação em espaços da área da saúde. A frequente utilização da terceira pessoa no discurso de muitas entrevistadas, indicando a percepção de discriminação, nos serviços de saúde, em relação a terceiros, mas não em si mesmas, pode sugerir tal influência.

Há que se discutir, ainda, como sugeriu uma das entrevistadas, se a discriminação nos serviços de saúde se deve ao fato da nacionalidade boliviana, ou se o fato de ser estrangeira faz aumentar uma atitude negativa já corrente em relação a grupo de nacionais brasileiros que também se encontram à margem da sociedade e sofrem, a seu modo, desrespeitos semelhantes. Seriam alguns maus-tratos, resultantes de uma limitação específica do SUS para com a população de bolivianas ou uma restrição/dificuldade estrutural do sistema perceptível também em relação a certos perfis de brasileiras?

A presença de estranhamentos mútuos entre a população nacional e os imigrantes internacionais e os grandes desafios de integração da comunidade boliviana na cidade de São Paulo são, ainda, uma realidade a ser enfrentada por ambas as partes. Mas ao longo destes aproximados sessenta anos da presença destes imigrantes na cidade, é possível indicar avanços na ocupação de espaços públicos.

Não é preciso mais ir ao Brás, Pari, Canindé ou Bom Retiro, bairros conhecidos pela forte incidência desta população, para perceber sua presença na cidade. Para além da Feira da Praça Kantuta, situada entre as ruas Pedro Vicente Carnot e das Olarias, no bairro do Pari, e da Rua Coimbra, no bairro do Brás, pode-se notar a presença de bolivianos e bolivianas, ainda que discreta, em determinados ambientes, nos meios de transporte públicos, nas ruas, nos parques, em determinados shoppings, em feiras livres, em escolas (públicas ou particulares), em hospitais e postos de saúde, dentre outros.

Desta forma, a iniciativa de conhecer a comunidade boliviana e tentar alcançar as suas necessidades na cidade de São Paulo, por parte de escolas e universidades, bem como por organizações da sociedade civil, pode lograr demonstrar que a existência desta população numerosa na cidade demanda a concretização de medidas apropriadas às suas necessidades.

Neste sentido, o presente estudo tentou trazer contribuições e elementos para subsidiar uma discussão mais ampla, na sociedade civil e no poder público, em relação à comunidade de bolivianos residente na cidade de São Paulo, particularmente em relação às mulheres bolivianas em seus contatos com os serviços de saúde. 
Este artigo, sem qualquer pretensão de esgotar um tema de tamanha relevância, tratou de conhecer tão somente alguns aspectos desta mesma população em São Paulo, podendo induzir, entretanto, estudos com novas perspectivas e discussões em diferentes esferas sobre a relevância deste fenômeno migratório, tanto para os imigrantes, como para a sociedade brasileira.

\section{Agradecimentos}

Gostaria de agradecer a orientação da professora Ana Lúcia Pastore Schritzmeyer; ao apoio de toda a equipe do Centro de Apoio ao Migrante (CAMI), em especial, ao Paulo Illes, e a todas as mulheres imigrantes que colaboraram com a realização das entrevistas.

\section{REFERÊNCIAS BIBLIOGRÁFICAS}

ANISTIA a estrangeiros irregulares atende expectativa do governo. Disponível em: <http://portal.mj.gov.br/data/Pages/MJA5F550A5ITEMIDBA915BD3 AC384F6C81A1AC4AF88BE2D0PTBRNN.htm>. Acesso em: 10 jun. 2010.

BRASIL. Ministério da Saúde. Secretaria de Atenção à Saúde. Departamento de Ações Programáticas Estratégicas. Legislação em saúde: caderno de legislação de saúde do trabalhador. 2. ed. rev. ampl. Brasília: Ministério da Saúde, 2005.

BRITO, Fausto. Os povos em movimento: as migrações internacionais no desenvolvimento do capitalismo. In: PATARRA, Neide Lopes (Coord.). Emigração e imigração internacionais no Brasil contemporâneo. 2. ed. São Paulo: FNUAP, 1995. p. 53-66.

CAHALI, Yussef Said. Estatuto do Estrangeiro. São Paulo: Saraiva, 1983.

CAVALCANTI, Leonardo. Imigrante na cidade: paradoxos e pleonasmos. Travessia: revista do migrante, São Paulo, ano 18, n. 51, p. 21-26, jan./abr. 2005.

COMISSÃO MUNDIAL SOBRE AS MIGRAÇÕES INTERNACIONAIS. As migrações num mundo interligado: novas linhas de ação. 2005. Disponível em: <http://www.mte.gov.br/cni/relatorioglobal.pdf>. Acesso em: 20 ago. 2008.

DAHROUGE, Simone et al. An evaluation of gender equity in different models of primary care practices in Ontario. BCM Public Health, Londres, v. 10. 2010. Disponível em: <http://www.biomedcentral.com/1471-2458/10/151>. Acesso em: 07 mar. 2010. 
DALLARI, Sueli Gandolfi. Direito sanitário. Disponível em: <http:// www.saude.ba.gov.br/conferenciaST2005/cdrom/CD\%20colet\%C3\%A2nea\% 20leis\%20e\%20textos/Artigos/10.doc>. Acesso em: 30 out. 2006.

FUSCO, Wilson; SOUCHAUD, Sylvain. Uniões exogâmicas dos imigrantes bolivianos na fronteira do Brasil. Travessia: revista do migrante, São Paulo, ano 22, n. 63, p. 32-38, jan./abr. 2009.

GONÇALVES, Aldina et. al. Acesso aos cuidados de saúde de comunidades migrantes: problemas e perspectivas de intervenção. Revista Portuguesa de Saúde Pública, Lisboa, v. 21, n. 1, p. 55-64, jan.jun. 2003. Disponível em: <http://www.ensp.unl.pt/dispositivos-de-apoio/cdi/cdi/sector-de-publicacoes/ revista/2000-2008/pdfs/1-06-2003.pdf>. Acesso em: 5 jun. 2010.

GRAEME, Hugo. Migrações internacionais não-documentadas: uma tendência global crescente. Travessia: revista do migrante, São Paulo, ano 11, n. 30, p. 5-12, jan./abr. 1998.

JARDIM, Denise Fagundes (Org.). Cartografias da imigração: interculturalidade e políticas públicas. Porto Alegre: Ed. UFRGS, 2007.

MADI, Maria Carolina C.; CASSANTI, Ana Carolina; SILVEIRA, Cássio. Estudo das representações sociais sobre gestação em mulheres bolivianas no contexto da atenção básica em saúde na área central da cidade de São Paulo. Saúde Sociedade, São Paulo, v. 18, supl. 2, p. 67-71, abr.jun. 2009. SciELO Brasil. Disponível em: <http://www.scielo.br/scielo.php?script=sci_ arttext\&pid=S0104-12902009000600011\&lng=pt\&nrm=iso >. Acesso em: 05 jun. 2010.

MENEZES, Lená Medeiros. Movimentos e políticas migratórias em perspectiva histórica: um balanço do século XX. In: CASTRO, Mary Garcia (Coord.). Migrações internacionais: contribuições para políticas. Brasília: CNPD, 2001. p. 123-136.

MONTANHANA, Beatriz. A constitucionalização dos direitos sociais: a afirmação da dignidade do trabalhador. In: FREITAS JUNIOR, Antonio Rodrigues de (Org.). Direito do trabalho e direitos humanos. São Paulo: BH Ed. e Distribuidora de Livros, 2006. p. 63-109.

MONTEIRO, Ivete. Ser mãe Hindu: práticas e rituais relativos à maternidade e aos cuidados à criança na cultura Hindu em contexto de imigração. Dissertação (Mestrado em Comunicação em Saúde) - Universidade Aberta, Lisboa, 2005. (Observatório da Imigração, Colecção Teses, Tese nr. 9. Lisboa: ACIDI).

NOVAIS, Denise Pasello Valente. Tráfico de pessoas para fins de exploração do trabalho no Brasil: um estudo sobre a exploração do trabalho de bolivianos em condição análoga à de escravo na cidade de São Paulo. 2008. 201f. Tese (Doutorado em Direito do Trabalho) - Universidade de São Paulo, São Paulo, 2008. 
OLIVEIRA, Sebastião Geraldo. Proteção jurídica à saúde do trabalhador. São Paulo: LTr, 2002.

PROGRAMA DAS NAÇÕES UNIDAS PARA O DESENVOLVIMENTO - PNUD. Relatório de Desenvolvimento Humano. Ultrapassar barreiras: mobilidade e desenvolvimento humanos. 2009. Disponível em: <http://hdr.undp.org/en/ media/HDR_2009_PT_Complete.pdf> Acesso em: 5 jun. 2010.

ROCHA-TRINDADE, Maria Beatriz. (Org.). Sociologia das migrações. Lisboa: Universidade Aberta, 1995.

SILVA, Elaine Cristina Camillo. Rompendo barreiras: os bolivianos e o acesso aos serviços de saúde na cidade de São Paulo. Travessia: revista do migrante, São Paulo, ano 22, n. 63, p. 26-31, jan./abr. 2009.

SILVA, Sidney Antonio. Costurando sonhos: trajetória de um grupo de imigrantes bolivianos em São Paulo. São Paulo: Paulinas, 1997.

SILVA, Sidney Antonio. Hispano-americanos em São Paulo: alcances e limites de um processo de integração. Travessia: revista do migrante, São Paulo, ano 12, n. 33, p. 24-32, jan./abril 1999.

VADE MECUM SARAIVA. 7. ed. São Paulo: Saraiva, 2009.

\section{ANEXO 1}

\begin{tabular}{|c|c|c|c|c|c|c|c|}
\hline \multicolumn{5}{|c|}{ DATOS GENERALES } & \multicolumn{2}{|l|}{ FECHA } & 11 \\
\hline \multicolumn{8}{|c|}{ NOMBRE COMPLETO } \\
\hline \multicolumn{8}{|c|}{ NOMBRE DE LA MADRE } \\
\hline \multicolumn{8}{|c|}{ NOMBRE DEL PADRE } \\
\hline \multicolumn{2}{|c|}{ PAÍS DONDE NACIÓ } & \multicolumn{2}{|c|}{ CIUDAD DONDE NACIÓ } & \multicolumn{2}{|c|}{ FECHE DE NACIMIENTO } & \multicolumn{2}{|c|}{ DOC. DE IDENTIDAD N. } \\
\hline \multicolumn{8}{|c|}{ DIRECCIÓN (AV/RUA) } \\
\hline \multicolumn{2}{|l|}{ BARRIO } & \multicolumn{4}{|l|}{ CEP } & \multicolumn{2}{|c|}{ CIUDAD } \\
\hline \multicolumn{2}{|l|}{ TELEFONO } & \multicolumn{4}{|c|}{ CELULAR } & & \\
\hline \multicolumn{2}{|c|}{$\begin{array}{l}\text { ¿EN QUE TRABAJABA } \\
\text { EN SUS PAIS? }\end{array}$} & & & \multicolumn{2}{|c|}{$\begin{array}{l}\text { ¿EN QUE TRABAJA } \\
\text { ACTUALMENTE? }\end{array}$} & & \\
\hline \multicolumn{8}{|l|}{$\begin{array}{l}\text { GRADO DE } \\
\text { ESCOLARIDAD: }\end{array}$} \\
\hline \multicolumn{2}{|c|}{$\begin{array}{l}\text { EN QUE FECHA } \\
\text { INGRESO AL PAÍS }\end{array}$} & & & \multicolumn{2}{|c|}{$\begin{array}{l}\text { ¿POR QUE CIUDAD } \\
\text { INGRESASTE AL PAÍS }\end{array}$} & & \\
\hline \multicolumn{4}{|c|}{ MODO DE INGRESO AL PAIS } & \multicolumn{4}{|c|}{ MOTIVO DE VENIR A BRASIL } \\
\hline OMNIBUS $\square$ & AVIOI & $N \square$ & OUTRO $\square$ & TRABAJO $\square$ & ESTUD & $\square$ & OTROS $\square$ \\
\hline
\end{tabular}


PARA USO ESPECÍFIO DE LOS AGENTES DEL CENTRO DE APOYO AL MIGRANTE

\begin{tabular}{|l|l|l|l|l|}
\hline \multicolumn{5}{|c|}{ MOTIVO DE VENIR AL CENTRO DE APOYO AL MIGRANTE } \\
\hline INFORMACIÓN & DOCUMENTACIÓN & FORMACIÓN & DENUNCIA \\
\hline DESCRIPCIÓN DE ATENDIMIENTO POR LOS AGENTES: \\
\hline PARECER ABOGADOS/AS
\end{tabular}

FIRMA DEL INTERESADO:

ANEXO 2

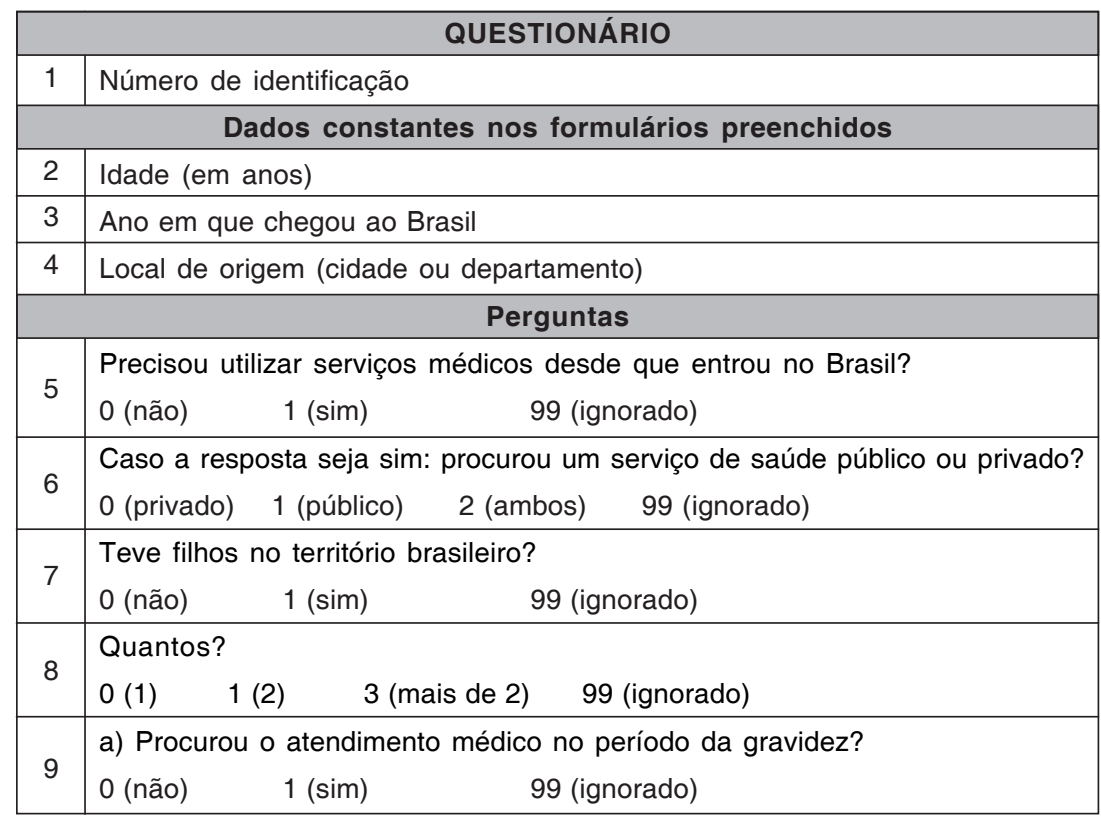




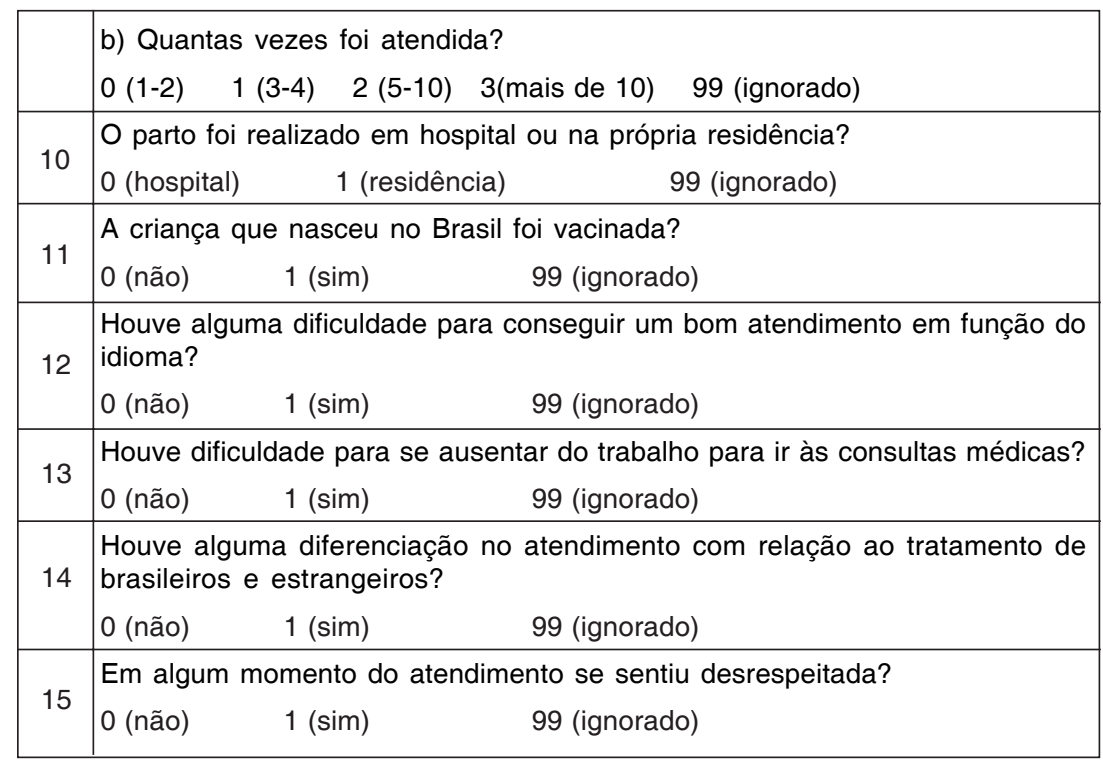

